\title{
A Scoping Review on Studies of Cyberbullying Prevalence Among Adolescents
}

TRAUMA, VIOLENCE, \& ABUSE 2017, Vol. I8(5) 523-531 (C) The Author(s) 2016 Reprints and permission: sagepub.com/journalsPermissions.nav DOI: $10.1177 / 1524838016641668$ journals.sagepub.com/home/tva (S)AGE

\author{
Sandra Brochado', Sara Soares', and Sílvia Fraga'
}

\begin{abstract}
This descriptive scoping aims to understand how the prevalence of cyberbullying has been estimated across studies. A systematic scoping review of cyberbullying empirical studies was conducted by using three bibliographic databases to search for papers published between January 2004 and August 20I4. A protocol was defined to identify the relevant papers. Papers selected were included in a data sheet developed by the authors to record specific findings. In total, 159 studies were included in the scoping review. Most of the prevalence studies were conducted in the last 4 years, mainly in North America $(n=77)$ and in Europe $(n=65)$. High methodological heterogeneity was found among the studies, which may contribute to explain variability in prevalence estimates. Cyberbullying experiences were assessed through several different perspectives: focused only on victims, focused only on perpetrators, or focused on both victims and perpetrators (without differentiating between if they are victims or perpetrators). Most of the studies tend to assess cybervictimization experiences. However, even considering the same perspective, the same country, and the same recall period, a high variability in the estimates was observed. As a main conclusion, the way in which the prevalence of cyberbullying is estimated is influenced by methodological research options.
\end{abstract}

\section{Keywords}

violence, cyberbullying, adolescents, scoping review

\section{Introduction}

Cyberbullying is a form of aggression in which electronic means, such as e-mail, mobile phone calls, text messages, instant messenger contact, photos, social networking sites, and personal webpages, are used with the intention of causing harm to another person through repeated hostile conduct (Ortega et al., 2012).

Most adolescents and young adults use social networks and mobile phones to communicate and interact with each other (Kiriakidis \& Kavoura, 2010). Consequently, the widespread use of technologies has complexified interpersonal relationships by making changes in the forms of communication that have evolved from face-to-face to online interactions. This evolution, although positive in bringing together people who are geographically apart, also has a negative side, such as cyberbullying, that may result from easy access and therefore abuse of technology (Nixon, 2014).

Although cyberbullying is a relatively new field in research, it has been suggested that cyberbullying among adolescents is associated with a greater risk of psychological, behavior, and health problems (Gamez-Guadix, Smith, Orue, \& Calvete, 2014; Nixon, 2014; Sinclair, Bauman, Poteat, Koenig, \& Russell, 2012; Völlink, Bolman, Dehue, \& Jacobs, 2013; Ybarra \& Mitchell, 2004) and a high risk of suicide (Bonanno \& Hymel, 2013; Messias, Kindrick, \& Castro, 2014; Sampasa-Kanyinga,
Roumeliotis, \& Xu, 2014; Sinclair et al., 2012). In addition, the Centers for Disease Control and Prevention (2014) has already considered cyberbullying to be a serious public health threat among youth. Therefore, this recent phenomenon deserves particular attention, given the consequences it may bring to adolescents' well-being and health.

Besides the possibility of perpetrators remaining anonymous (Baas, de Jong, \& Drossaert, 2013; Huang \& Chou, 2010; Williams \& Guerra, 2007), cyberbullying also has the potential of a widespread accessibility of victims and an infinite audience through the use of communication technologies (Shariff \& Hoff, 2007).

However, the lack of an established definition and consequently difficulty in operationalizing it may undermine the acquisition of accurate and comparable estimates across studies.

Despite increased interest in this topic, there has been little discussion about estimates of cyberbullying prevalence. Thus,

\footnotetext{
'Epidemiology Research Unit (EPI-Unit), Institute of Public Health, University of Porto, Porto, Portugal

Corresponding Author:

Silvia Fraga, Institute of Public Health, University of Porto, Rua das Taipas, I35, 4050-600 Porto, Portugal.

Email: silfraga@med.up.pt
} 
we undertook a descriptive systematic scoping review of the literature to understand how the prevalence of cyberbullying has been estimated across studies.

\section{Method}

The current scoping review was guided by the methodological framework proposed by Arksey and O'Malley (2005). The framework outlines a five-stage approach including identifying the research question; searching for relevant studies; selecting studies; charting data; and collating, summarizing, and reporting the results.

\section{Identifying the Research Questions (Stage I)}

To guide the current scoping review, we focused on the following main research question: How has the prevalence of cyberbullying been estimated across studies?

\section{Identifying Relevant Studies (Stage 2)}

We conducted a scoping review on cyberbullying by searching PubMed $^{\mathbb{R}}$, PsycINFO ${ }^{\mathbb{R}}$, and Web of Science ${ }^{\mathrm{TM}}$ for peerreviewed literature publications between January 2004 and August 2014. We used the following broad-based research expression ("cyberbullying" OR "cyber-bullying" OR "Internet harassment" OR "Internet bullying"), which was adjusted for each database. Upon completion, the searches from each database were documented, and references were imported into database-specific folders where duplicates were eliminated.

\section{Selection of Studies (Stage 3)}

The strategy used retrieved 808 articles. Duplicates were removed $(n=302)$ and the remaining articles $(n=506)$ were reviewed by two authors (SB and SS). Through a preliminary search, two independent authors (SB and SS) reviewed the title and abstracts and those that did not address the research question of the study were excluded $(n=238)$. At this stage of the review, any uncertainty with a title and abstract would not eliminate the study.

Then, a total of 268 studies were forwarded to the next stage of screening. In this step, studies were excluded if they (1) were not published in English, French, Portuguese, or Spanish; (2) focused on specific populations such as individuals with chronic illness or physical or mental disabilities; (3) focused on sexual orientation-related or workplace bullying; (4) did not focus on adolescence; or (5) were reviews or experimental or intervention studies (109 studies were excluded for any one of these reasons). The full text of studies assessed as relevant or unclear was independently evaluated by two reviewers (SB and SS). Discrepancies were resolved by consensus or a third party (SF). This scoping review includes 159 full articles focused on prevalence. The Preferred Reporting Items for Systematic Reviews and Meta-Analyses checklist (Moher, Liberati, Tetzlaff, \& Altman, 2009) and flow diagram were used as a guide in the reporting of this scoping review (presented in Figure 1).

\section{Charting Data (Stage 4)}

We collected and sorted key pieces of information from the selected articles. Data to be extracted from the large quantity of published research literature included standard information such as author, year of publication, country, sample size, age, and methodology (data available upon request). Additionally, information on prevalence (by gender, if available), recall period, and instrument used to assess cyberbullying were extracted from the articles.

\section{Collating, Summarizing, and Reporting Results (Stage 5)}

We synthesized the data according to the research question previously defined. The increase of publications in the last years and the geographic distribution of studies performed were initially described using graphs. Then, the cyberbullying prevalence was summarized and shown according to country, instrument used, recall periods (defined by the survey question that could cover different periods: lifetime, last year, last 6 months, last month, or last week), and type of involvement (only victims, only aggressors, and both victims and perpetrators).

\section{Results}

The publication of studies on cyberbullying has been increasing over the years. As shown in Figure 2, the first studies on this topic were published in 2004 and their number increased progressively until 2010. A 3-fold increase was observed between 2011 and 2012 when compared with 2010. Overall, the studies are distributed worldwide; the highest number of prevalence studies was carried out in North American countries (77 studies, with 61 coming from the United States), followed by European countries (65 studies, with 13 studies conducted in Spain; data available upon request).

\section{Cyberbullying Prevalence}

Among the prevalence studies ( $n=159$ studies), we found that cyberbullying experiences were assessed from several different perspectives: victims (focused only on the assessment of victims of cyberbullying episodes), perpetrators (focused only on the assessment of perpetrators of cyberbullying episodes), and both victims and perpetrators (focused on these experiences without differentiating between victims and perpetrators). However, most of the studies tended to assess the experiences of cybervictimization.

Figure 3 shows the prevalence according to country including only those countries with five or more studies. A high variability in the estimates of cyberbullying was observed between and within countries regarding the nature of cyberbullying involvement. The highest median prevalence was found in the group of studies from Canada $23.8 \%$, varying between $1.9 \%$ and $65.0 \%$ ) and China (23.0\%, varying between $11.2 \%$ and $56.9 \%$ ) when considering victims, while the lowest median prevalence was observed in studies from Australia (5.0\%), Sweden (5.2\%), and Germany (6.3\%). 


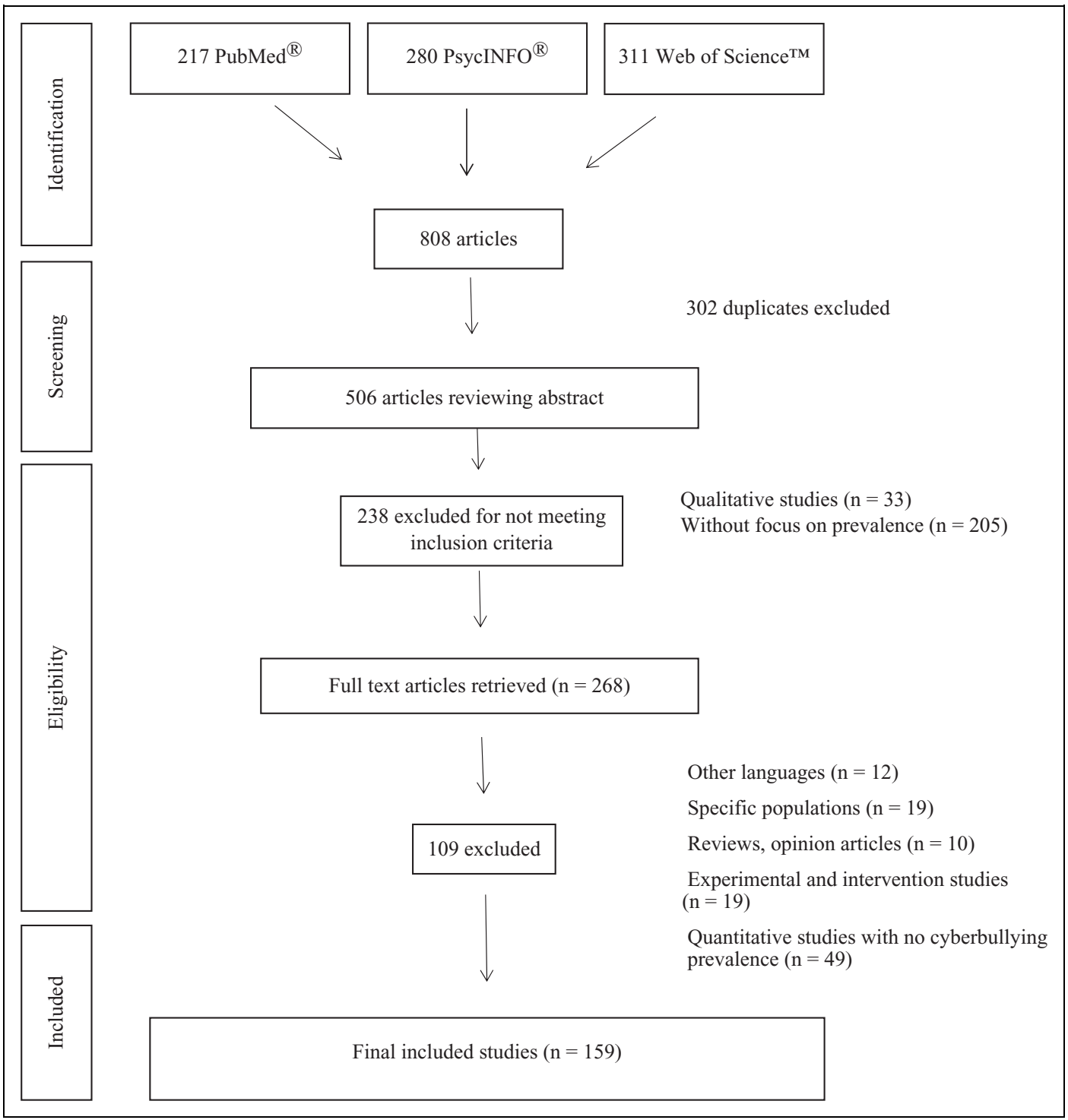

Figure I. Flow diagram of the study selection process.

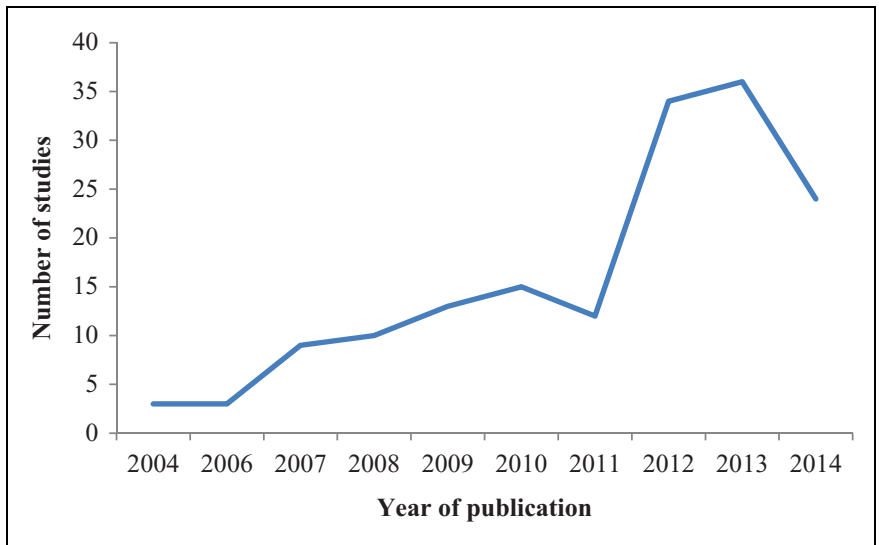

Figure 2. Line graph showing the number of prevalence studies published per year since 2004.
We observed that among prevalence studies, different recall periods were used. Most studies asked about victims' experiences in the last year $(n=55)$ and in the last 6 months $(n=49$ studies). With regard to the former recall period, overall victimization varied from $1.0 \%$ to $61.1 \%$, perpetration from $3.0 \%$ to $39.0 \%$, and both victims and perpetrators varied from $1.5 \%$ to $72.0 \%$. If the last 6 months were considered, the prevalence of victimization varied from $1.6 \%$ to $56.9 \%$ and perpetration varied from $1.9 \%$ to $79.3 \%$. Although only a few studies showed results stratified by gender, the available information showed that last year victimization among females ranged from $3.7 \%$ to $36.0 \%$, and among males from $1.8 \%$ to $28.4 \%$, while aggression varied between $3.7 \%$ and $9.0 \%$, and $0.9 \%$ and $20.4 \%$ for girls and boys, respectively. Also, the studies defined adolescents differently (e.g., ages $12-18$, ages $10-17$, ages $12-15$ ), which may explain some of the variability across studies. 


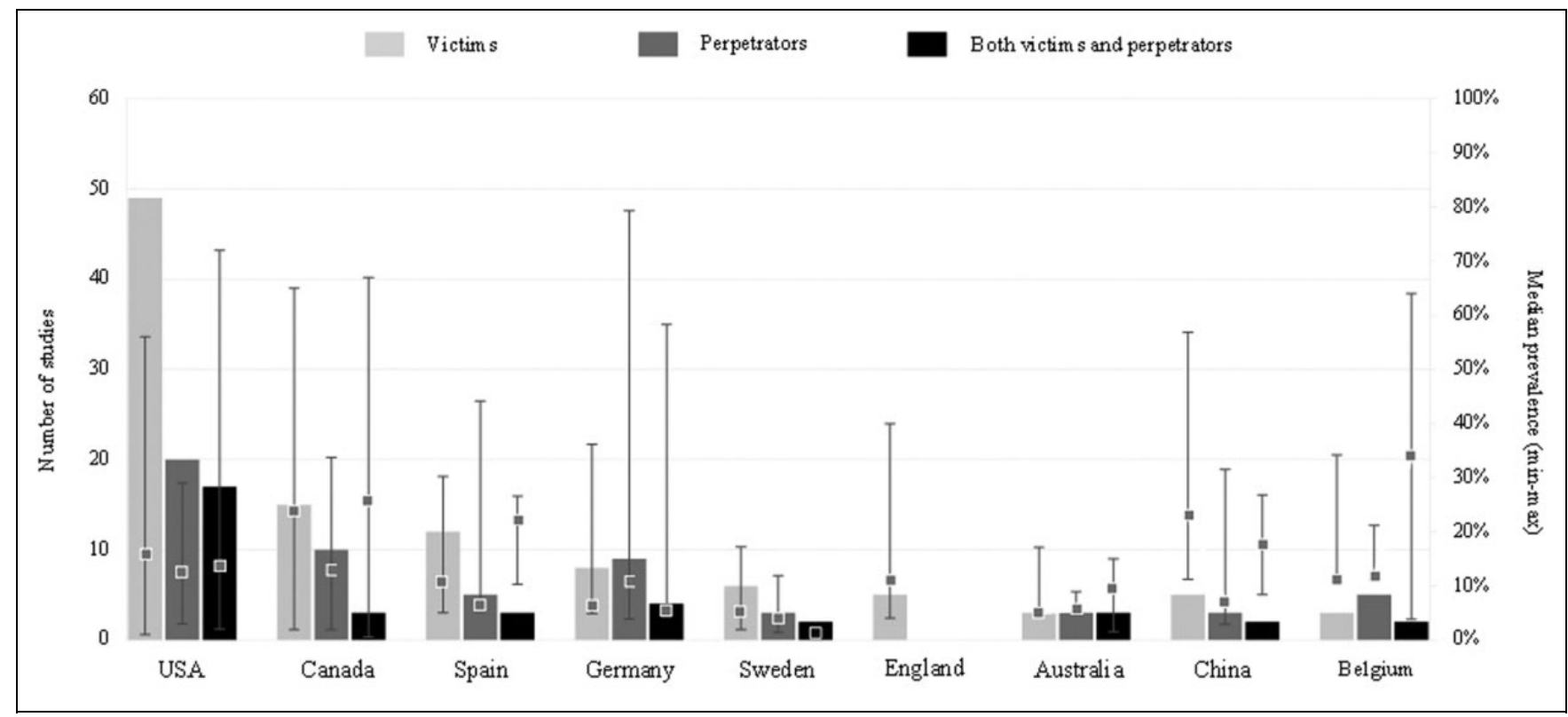

Figure 3. Number of cyberbullying studies according to country and type of prevalence: victims, perpetrators, and both victims and perpetrators (including only countries with $\geq 5$ studies).

Table I. Cyberbullying Prevalence According to Different Recall Periods and to the Type of Involvement Assessed (Victims, Perpetrators, and Both Victims and Perpetrators).

Prevalence Range

\begin{tabular}{|c|c|c|c|c|c|c|}
\hline \multirow[b]{2}{*}{ Recall Periods } & \multicolumn{6}{|c|}{ Prevalence Range } \\
\hline & $n$ & Victims (\%) & $n$ & Perpetrators (\%) & $n$ & Both Victims and Perpetrators (\%) \\
\hline \multicolumn{7}{|c|}{ Lifetime $(n=4 I)$} \\
\hline Overall & 33 & $4.9-65.0$ & 19 & $1.2-44.1$ & 14 & $5.0-64.3$ \\
\hline Female & 7 & $2.6-61.0$ & 7 & $4.5-52.4$ & 2 & $5.8-45.1$ \\
\hline Male & 7 & $3.3-46.5$ & 7 & $6.1-47.6$ & 2 & $16.3-54.9$ \\
\hline \multicolumn{7}{|c|}{ Last year $(n=55)$} \\
\hline Overall & 42 & $1.0-61.1$ & 20 & $3.0-39.0$ & 17 & $1.5-72.0$ \\
\hline Female & 8 & $3.7-36.0$ & 4 & $3.7-9.0$ & 2 & $5.1-23.6$ \\
\hline Male & 8 & 1.8-28.4 & 4 & $0.9-20.4$ & 2 & $5.2-15.1$ \\
\hline \multicolumn{7}{|c|}{ Last 6 months $(n=49)$} \\
\hline Overall & 38 & $1.6-56.9$ & 25 & 1.9-79.3 & 21 & $0.5-63.4$ \\
\hline Female & 11 & $1.4-36.3$ & 4 & $1.3-5.6$ & 5 & $0.3-7.3$ \\
\hline Male & II & $0.6-32.4$ & 4 & $1.1-9.3$ & 5 & $0.2-11.1$ \\
\hline \multicolumn{7}{|c|}{ Last month $(n=13)$} \\
\hline Overall & 10 & $5.30-31.3$ & 9 & $4.9-31.5$ & 3 & $19.0-60.0$ \\
\hline Female & 2 & $12.8-17.0$ & I & 14.8 & 0 & - \\
\hline Male & 2 & $11.0-13.4$ & 1 & 16.0 & 0 & - \\
\hline \multicolumn{7}{|c|}{ Last week $(n=1)$} \\
\hline Overall & 1 & 14.4 & I & 2.9 & I & 8.4 \\
\hline Female & 0 & - & 0 & - & 0 & - \\
\hline Male & 0 & - & 0 & - & 0 & - \\
\hline
\end{tabular}

However, the association between age and cyberbullying was not consistent across studies (presented in table 1).

\section{Discussion}

This descriptive scoping review allowed for the identification of studies on cyberbullying and how these studies are distributed worldwide as well as the description of the prevalence of cyberbullying among adolescents and how it differs according to different contexts and methodological options. This may be helpful to better understand how prevalence studies have been conducted, by discussing the main difficulties associated with achieving consensus and maximizing comparability among studies. 
Our option of using a broad research expression in our scoping strategy is related with our concern of covering all published papers, as we are aware that the first studies may not be indexed using the key word "cyberbullying." Our strategy was to assess a larger number of published studies even if we had to exclude them later. Also, although we are analyzing studies published over a decade, the majority were published in the last 4 years. The publication of scientific articles addressing this phenomenon has been increasing, with a substantial rise observed between 2011 and 2012. A possible explanation for this increase may be the real rise in research on this topic during this period but also the indexation of the key word cyberbullying, which started later in some databases. Most studies were conducted in North America (United States and Canada) followed by Europe (mostly in Spain). The differences across countries or regions may be explained by, on the one hand, the impact some campaigns had in media or cyberbullying suicide cases (Lester, McSwain, \& Gunn, 2013; Pokin, 2007) that occurred in these countries and therefore increased awareness and exposure. On the other hand, the low occurrence and visibility of this phenomenon in some regions explain the lack of studies. Also, we cannot discard that some papers on cyberbullying prevalence may be published in databases different from those included in this scoping review. Besides, we should note that for the country analysis, we only considered countries that had five or more studies on cyberbullying, which limits the country comparison. Our option of including countries with five studies was based on the distribution of studies across countries. Also, the language criteria may hamper the inclusion of countries that may have publications in other languages.

We found that the prevalence of cyberbullying varied greatly from country to country which may reflect real differences in its occurrence across countries. In fact, differences in cyberbullying across countries are expected because this phenomenon is significantly influenced by cultural contexts (Barlett et al., 2014). However, our analysis also showed differences in prevalence within countries. This large intracountry variability may create difficulty in obtaining the real prevalence estimate for each country. Although some of the differences may be explained by regional intracountry differences, the use of different methods or research strategies could have contributed to the observed variability. In line with other publications, we should also note that most of the countries have a small number of studies which may contribute to high variability in the estimates, while countries with a high number of studies seem to show lower variability in the estimates (Hamm et al., 2015).

Additionally, the use of different options related to recall period (lifetime, last year, last 6 months, last month, or last week), different perspectives of cyberbullying experience (victims, perpetrators, or both victims and perpetrators), and different instruments (scales or study-specific questions that are developed by authors) may contribute to the differences observed between studies.
Although it was not a focus of this scoping review, we observed that most studies have used questions developed by respective study authors to measure the prevalence of cyberbullying. However, some studies used questions from large-scale surveys to measure the prevalence of cyberbullying. The Youth Internet Safety Survey and the Youth Risk Behavior Survey were the most commonly used questionnaires.

A previous review on instruments used to measure cyberbullying showed that the diversity of instruments is also a consequence of a lack of consensus regarding the concept and its definition (Berne et al., 2013), which may also be related to the variability in cyberbullying estimates. Consequently, we found it difficult to compare the median prevalence assessed by different instruments. The inconsistency in a cyberbullying definition (Ortega et al., 2012; P. K. Smith et al., 2008) and the consequent difficulty in operationalizing it may contribute to the development of multiple instruments to measure the prevalence of cyberbullying (Berne et al., 2013). The development of a standard instrument to measure cyberbullying that may be culturally adapted, allowing for the comparison of prevalence across settings, would be useful.

Given that it was not possible to establish a comparison of prevalence estimates obtained through the different instruments used, we have described the estimates according to the different study options. When authors designed their own instruments, a high variability was still observed. Although the most used recall period was the last year, lifetime and the last 6 months were also used quite often as options. Even when limiting the analysis to the same recall period or the same instruments, a high variability in the estimates was obtained. This may be explained by cultural differences or by other factors related to the study procedures that we were unable to identify. In our analysis, we only considered the occurrence of at least one event during the different recall periods used; however, there are also studies assessing the frequency of cyberbullying events within each period (Heirman \& Walrave, 2012; P. K. Smith et al., 2008; Vanden Abeele \& de Cock, 2013; Wachs, Wolf, \& Pan, 2012).

Additionally, the assessment of different perspectives of cyberbullying experiences also contributes to the challenge in establishing a comparison between studies and countries. When authors design the assessment questionnaire, they must clearly define the type of cyberbullying involvement, for instance, victims, perpetrators, or both victims and perpetrators. However, our analysis showed a high variability in the estimates even when results were stratified by the type of involvement.

This descriptive scoping showed that most studies focused on cyberbullying victims only. As in other types of violence, researchers tend to address violence through the perspective of the victim (Estevez, Musitu, \& Herrero, 2005; P. H. Smith, White, \& Holland, 2003), probably because there is a higher propensity to look at the magnitude of the problem considering those who were injured rather than those who attacked. Although we were unable to compare victims' and perpetrators' estimates because of differences in the number of studies 
and methodological issues, we can expect to find large differences between these two types of involvement. Victims may better disclose their experience than aggressors, although fear of embarrassment or punishment may contribute to underreporting (DeSmet et al., 2014). Aggressors are likely to underreport their behavior because it is easy to hide (Aboujaoude, Savage, Starcevic, \& Salame, 2015) and they may also fear punishment.

Additionally, studies that assessed involvement in cyberbullying, assuming the involvement can include victim only, perpetrator only, or both victims and perpetrators, may be criticized by some researchers because they do not allow to disentangle who the victim was and who the aggressor was, and, in fact, the consequences may be different. However, recent approaches tend to show some concurrence in rates of perpetration and victimization, and mainly an overlap in the rates indicating that those who are victims are also aggressors (C. T. Allen, Swan, \& Raghavan, 2009; Straus \& Ramirez, 2007). Although some concurrence usually seems to exist in violent behaviors among adolescents, the context in which these episodes may occur is difficult to assess. We do not know if they become aggressors in a self-defense situation (Varjas, Talley, Meyers, Parris, \& Cutts, 2010), or if they were aggressors in one episode and victims in another $(\mathrm{Li}, 2007)$. Indeed, in terms of prevention strategies, we believe that the most efficient strategy would be working on cyberbullying as a general problem, by helping adolescents deal with the problem, whether victim, aggressor, or even bystander.

There is some inconsistency in the literature with regard to the role of gender in the cyberbullying phenomenon. Some studies show that rates of victimization are higher among girls (Buelga, Cava Maria, \& Musitu, 2010; Elledge et al., 2013; Fenaughty \& Harré, 2013). However, other studies show that rates are higher among boys (Calvete, Orue, Estévez, Villardón, \& Padilla, 2010; Campbell, Slee, Spears, Butler, \& Kift, 2013). In this scoping, only a small number of studies presented estimates according to gender, which makes it difficult to draw any conclusion regarding gender differences. Also, we may speculate that inconsistency in gender differences may be related to the study, or it could mean that cyberbullying is a problem that occurs regardless of gender.

This review only included studies on adolescents, which represent the most studies performed in the topic of cyberbullying. Only a small number of studies were conducted in other population groups such as children or young adults. The studies defined adolescents differently (e.g., ages $12-18$, ages $10-17$, ages 12-15). Other studies used school grade instead of age for sample selection (data available upon request). Although we are only including studies covering the period of adolescence, the different age ranges used may have affected prevalence estimates. It is not clear whether there would be differences in the level of cyberbullying among adolescents of different ages, although adolescents of different ages may have different access to technologies. Some studies suggested that involvement in cyberbullying increases with age (Patchin \& Hinduja, 2011; Santos Luque \& Romera Félix, 2013), while most studies that included adolescents whose ages varied widely have not found significant associations between cyberbullying and age (K. P. Allen, 2012; Campbell et al., 2013; Dittrick, Beran, Mishna, Hetherington, \& Shariff, 2013).

The variability found among all of the studies included in this scoping showed that it would be problematic to compare the estimates when combining all of the methodological options. Research on violence always arises many challenges, namely, in measuring violence experiences. It is often difficult to get a standard procedure and an instrument to be used in different settings and also even using a standard procedure may not work in different cultures.

The identification of cyberbullying also depends on how cyberbullying is defined by study participants, on how the questions are asked, and on the setting in which data are collected (Aboujaoude et al., 2015; P. K. Smith et al., 2008). We believe that adolescents' perception of cyberbullying may have an influence on prevalence results, particularly when the general questions were used to assess prevalence. If adolescents were asked about cyberbullying experiences, they may be concealing that they were victims when they really are. Thus, the use of a standardized instrument that asks about the occurrence of specific types of situations may be less influenced by adolescents' own definitions of cyberbullying.

We opted to conduct a scoping review because our goal was to understand how the prevalence of cyberbullying was estimated and what may be contributing to the variability observed. Our option focused on the description of these studies and also a discussion of different methodological options, instead of conducting refined statistical analysis. It was not our intention to conduct a meta-analysis that would lead to a quantitative summary of the results, given that the results needed to be judged sufficiently similar to support such a synthesis (Porta, 2008). Although published and indexed articles in major databases are expected to be methodologically sound, as they are peer reviewed, we believe that we found considerable variation in research quality.

There is a lack of studies on this topic in our country and therefore we are starting to invest in this field. Thus, in this scoping, we should note that we did not have to handle any of our own papers, given that we do not have any publications on this topic.

To sum up, we identified high heterogeneity among the prevalence studies that compromises comparability across countries. Also, among the countries with available data on prevalence, the comparison is difficult because of different methodological options. Different instruments, recall periods, and perspectives of involvement were identified among the studies, which limits cross-study and cross-country comparisons. As a main conclusion, the way in which the prevalence of cyberbullying is estimated is influenced by research methodology.

\section{Key Findings}

- Cyberbullying studies showed high heterogeneity in terms of prevalence estimates; 
- Several instruments have been designed and used to assess the prevalence, which reveals the difficulty in the assessment of this phenomenon;

- Different approaches of the phenomenon among adolescents were found across studies in terms of age range, recall periods, and perspectives of the cyberbullying experience, such as victimization only, perpetration only, or both.

\section{Recommendations for Research}

- Researchers should be cautious in the interpretation and comparison of studies on cyberbullying prevalence, particularly when they intend to generalize the results or establish comparisons between studies;

- Grounded on the increasing interest in cyberbullying among adolescents, the construction of a consistent definition of cyberbullying is recommended to ensure the standard operationalization and harmonization across studies;

- Although inconsistencies across studies were observed, this problem seems to be common and studies are scarce. Thus, it is recommended that the study of cyberbullying occurrence among adolescents continues by ensuring compliance with an accurate methodology;

- Effective policies for preventing cyberbullying must be firmly grounded in scientific research, thus making accurate estimates and consequently a valid identification of the phenomenon's magnitude essential for the development of programs to communicate preventive messages and for policy making.

\section{Declaration of Conflicting Interests}

The author(s) declared no potential conflicts of interest with respect to the research, authorship, and/or publication of this article.

\section{Funding}

The author(s) disclosed receipt of the following financial support for the research, authorship, and/or publication of this article: This study was supported by FEDER funding from the Operational Programme Factors of Competitiveness-COMPETE and by national funding from the FCT-Foundation for Science and Technology (Portuguese Ministry of Education and Science) within the project "Violence in various stages of life: Frequency, determinants and consequences of health" (ref. PTDC/SAU-SAP/122904/2010-FCOMP-01-0124FEDER-021439) and the Post Doc Grant to SF (SFRH/BPD/97015/ 2013).

\section{References}

Aboujaoude, E., Savage, M. W., Starcevic, V., \& Salame, W. O. (2015). Cyberbullying: Review of an old problem gone viral. Journal of Adolescent Health, 57, 10-18. doi:10.1016/j.jadohealth. 2015.04.011

Allen, C. T., Swan, S. C., \& Raghavan, C. (2009). Gender symmetry, sexism, and intimate partner violence. Journal of Interpersonal Violence, 24, 1816-1834. doi:10.1177/0886260508325496
Allen, K. P. (2012). Off the radar and ubiquitous: Text messaging and its relationship to 'drama' and cyberbullying in an affluent, academically rigorous US high school. Journal of Youth Studies, 15, 99-117. doi:10.1080/13676261.2011.630994

Arksey, H., \& O’Malley, L. (2005). Scoping studies: Towards a methodological framework. International Journal of Social Research Methodology, 8, 19-32. doi:10.1080/1364557032000119616

Baas, N., de Jong, M. D. T., \& Drossaert, C. H. C. (2013). Children's perspectives on cyberbullying: Insights based on participatory research. Cyberpsychology Behavior and Social Networking, 16, 248-253. doi:10.1089/cyber.2012.0079

Barlett, C. P., Gentile, D. A., Anderson, C. A., Suzuki, K., Sakamoto, A., Yamaoka, A., \& Katsura, R. (2014). Cross-cultural differences in cyberbullying behavior: A short-term longitudinal study. Journal of Cross-Cultural Psychology, 45, 300-313. doi:10.1177/ 0022022113504622

Berne, S., Frisén, A., Schultze-Krumbholz, A., Scheithauer, H., Naruskov, K., Luik, P., . . Zukauskiene, R. (2013). Cyberbullying assessment instruments: A systematic review. Aggression and Violent Behavior, 18, 320-334. doi:http://dx.doi.org/10.1016/ j.avb.2012.11.022

Bonanno, R. A., \& Hymel, S. (2013). Cyber bullying and internalizing difficulties: Above and beyond the impact of traditional forms of bullying. Journal of Youth and Adolescence, 42, 685-697. doi:10. 1007/s10964-013-9937-1

Buelga, S., Cava Maria, J., \& Musitu, G. (2010). Cyberbullying: Adolescent victimization through mobile phone and internet. Psicothema, 22, 784-789.

Calvete, E., Orue, I., Estévez, A., Villardón, L., \& Padilla, P. (2010). Cyberbullying in adolescents: Modalities and aggressors' profile. Computers in Human Behavior, 26, 1128-1135. doi:10.1016/j. chb.2010.03.017

Campbell, M. A., Slee, P. T., Spears, B., Butler, D., \& Kift, S. (2013). Do cyberbullies suffer too? Cyberbullies' perceptions of the harm they cause to others and to their own mental health. School Psychology International, 34, 613-629. doi:10.1177/01430343 13479698

Centers for Disease Control and Prevention. (2014, December 30). Electronic aggression-Technology and youth violence. Retrieved July 9, 2015, from http://www.cdc.gov/violenceprevention/youth violence/electronicaggression/

DeSmet, A., Veldeman, C., Poels, K., Bastiaensens, S., Van Cleemput, K., Vandebosch, H., \& De Bourdeaudhuij, I. (2014). Determinants of self-reported bystander behavior in cyberbullying incidents amongst adolescents. Cyberpsychology Behavior and Social Networking, 17, 207-215. doi:10.1089/ cyber.2013.0027

Dittrick, C. J., Beran, T. N., Mishna, F., Hetherington, R., \& Shariff, S. (2013). Do children who bully their peers also play violent video games? A Canadian national study. Journal of School Violence, 12, 297-318.

Elledge, L. C., Williford, A., Boulton, A. J., DePaolis, K. J., Little, T. D., \& Salmivalli, C. (2013). Individual and contextual predictors of cyberbullying: The influence of children's provictim attitudes and teachers' ability to intervene. Journal of Youth and Adolescence, 42, 698-710. doi:10.1007/s10964-013-9920-x 
Estevez, E., Musitu, G., \& Herrero, J. (2005). The influence of violent behavior and victimization at school on psychological distress: The role of parents and teachers. Adolescence, 40, 183-196.

Fenaughty, J., \& Harré, N. (2013). Factors associated with distressing electronic harassment and cyberbullying. Computers in Human Behavior, 29, 803-811. doi:10.1016/j.chb.2012.11.008

Gamez-Guadix, M., Smith, P. K., Orue, I., \& Calvete, E. (2014). Cyberbullying and psychological and behavioral health problems. Journal of Adolescent Health, 54, 618-619. doi:10.1016/j.jadohealth.2014.02.003

Hamm, M. P., Newton, A. S., Chisholm, A., Shulhan, J., Milne, A., Sundar, P., ... Hartling, L. (2015). Prevalence and effect of cyberbullying on children and young people: A scoping review of social media studies. JAMA Pediatrics, 169, 770-777. doi:10.1001/ jamapediatrics.2015.0944

Heirman, W., \& Walrave, M. (2012). Predicting adolescent perpetration in cyberbullying: An application of the theory of planned behavior. Psicothema, 24, 614-620.

Huang, Y.-y., \& Chou, C. (2010). An analysis of multiple factors of cyberbullying among junior high school students in Taiwan. Computers in Human Behavior, 26, 1581-1590. doi:10.1016/j.chb. 2010.06.005

Kiriakidis, S. P., \& Kavoura, A. (2010). Cyberbullying: A review of the literature on harassment through the Internet and other electronic means. Family \& Community Health, 33, 82-93. doi:10. 1097/FCH.0b013e3181d593e4

Lester, D., McSwain, S., \& Gunn, J. F., 3rd. (2013). Suicide and the Internet: The case of Amanda Todd. International Journal of Emergency Mental Health, 15, 179-180.

Li, Q. (2007). New bottle but old wine: A research of cyberbullying in schools. Computers in Human Behavior, 23, 1777-1791. doi:10. 1016/j.chb.2005.10.005

Messias, E., Kindrick, K., \& Castro, J. (2014). School bullying, cyberbullying, or both: Correlates of teen suicidality in the $2011 \mathrm{CDC}$ youth risk behavior survey. Comprehensive Psychiatry, 55, 1063-1068. doi:10.1016/j.comppsych.2014.02.005

Moher, D., Liberati, A., Tetzlaff, J., \& Altman, D. G. (2009). Preferred reporting items for systematic reviews and meta-analyses: The PRISMA statement. Annals of Internal Medicine, 151, 264-269, W264. doi:10.7326/0003-4819-151-4-200908180-00135

Nixon, C. L. (2014). Current perspectives: The impact of cyberbullying on adolescent health. Adolescent Health, Medicine and Therapeutics, 5, 143-158. doi:10.2147/ahmt.s36456

Ortega, R., Elipe, P., Mora-Merchan, J. A., Genta, M. L., Brighi, A., Guarini, A., ... Tippett, N. (2012). The emotional impact of bullying and cyberbullying on victims: A European Cross-National Study. Aggressive Behavior, 38, 342-356. doi:10.1002/ab.21440

Patchin, J. W., \& Hinduja, S. (2011). Traditional and nontraditional bullying among youth: A test of general strain theory. Youth \& Society, 43, 727-751. doi:10.1177/0044118x10366951

Pokin, S. (2007, November). 'My Space' hoax ends with suicide of Dardenne Prairie teen. St. Charles County Suburban Journal. Retrieved from http://www.stltoday.com/suburban-journals/ stcharles/news/stevepokin/my-space-hoax-ends-with-suicide-ofdardenne-prairie-teen/article_0304c09a-ab32-5931-9bb3210a5d5dbd58.HTML
Porta, M. (2008). A dictionary of epidemiology (5th ed.). New York, NY: Oxford University Press.

Sampasa-Kanyinga, H., Roumeliotis, P., \& Xu, H. (2014). Associations between cyberbullying and school bullying victimization and suicidal ideation, plans and attempts among Canadian schoolchildren. PLoS One, 9, e102145. doi:10.1371/journal.pone.0102145

Santos Luque, Á., \& Romera Félix, E. M. (2013). Influencia de la exposición a la violencia en conductas de agresión en cyberbullying [Influence of the exposure to violence in aggressive behaviors in cyberbullying]. Apuntes de Psicologia , 31, 225-235.

Shariff, S., \& Hoff, D. L. (2007). Cyber bullying: Clarifying legal boundaries for school supervision in cyberspace. International Journal of Cyber Criminology, 1, 76-118. doi:10.5281/zenodo. 18279

Sinclair, K. O., Bauman, S., Poteat, V. P., Koenig, B., \& Russell, S. T. (2012). Cyber and bias-based harassment: Associations with academic, substance use, and mental health problems. Journal of Adolescent Health, 50, 521-523. doi:10.1016/j.jadohealth.2011. 09.009

Smith, P. H., White, J. W., \& Holland, L. J. (2003). A longitudinal perspective on dating violence among adolescent and college-age women. American Journal of Public Health, 93, 1104-1109. doi: 10.2105/AJPH.93.7.1104

Smith, P. K., Mahdavi, J., Carvalho, M., Fisher, S., Russell, S., \& Tippett, N. (2008). Cyberbullying: Its nature and impact in secondary school pupils. Journal of Child Psychology and Psychiatry, 49, 376-385. doi:10.1111/j.1469-7610.2007.01846.x

Straus, M. A., \& Ramirez, I. L. (2007). Gender symmetry in prevalence, severity, and chronicity of physical aggression against dating partners by university students in Mexico and USA. Aggressive Behavior, 33, 281-290. doi:10.1002/ab.20199

Vanden Abeele, M., \& de Cock, R. (2013). Cyberbullying by mobile phone among adolescents: The role of gender and peer group status. Communications-European Journal of Communication Research, 38, 107-118. doi:10.1515/commun-20130006

Varjas, K., Talley, J., Meyers, J., Parris, L., \& Cutts, H. (2010). High school students' perceptions of motivations for cyberbullying: An exploratory study. Western Journal of Emergency Medicine, 11, 269-273.

Völlink, T., Bolman, C. A. W., Dehue, F., \& Jacobs, N. C. L. (2013). Coping with cyberbullying: Differences between victims, bullyvictims and children not involved in bullying. Journal of Community \& Applied Social Psychology, 23, 7-24. doi:10.1002/ casp. 2142

Wachs, S., Wolf, K. D., \& Pan, C. C. (2012). Cybergrooming: Risk factors, coping strategies and associations with cyberbullying. Psicothema, 24, 628-633.

Williams, K. R., \& Guerra, N. G. (2007). Prevalence and predictors of Internet bullying. Journal of Adolescent Health, 41, S14-S21. doi:10.1016/j.jadohealth.2007.08.018

Ybarra, M. L., \& Mitchell, K. J. (2004). Youth engaging in online harassment: Associations with caregiver-child relationships, Internet use, and personal characteristics. Journal of Adolescence, 27, 319-336. doi:10.1016/j.adolescence.2004. 03.007 


\section{Author Biographies}

Sandra Brochado completed a master degree in Health Education at University of Porto. She is interested in the violence topic, particularly bullying and cyberbullying among adolescents. Currently, she holds a research fellowship at the Institute of Public Health of University of Porto.

Sara Soares has a master in Pharmaceutical Medicine. She is currently pursuing a $\mathrm{PhD}$ programme in Public Health and she awarded a scholarship grant to conduct her research. Her research interest is related to the consequences of social adverse experiences in early life.

Sílvia Fraga completed her $\mathrm{PhD}$ in Public Health at University of Porto and is currently a post-doc researcher at the Institute of Public Health of University of Porto. Her main research interests include social inequalities in health, violence and the biology of social adversity. 